\title{
The Impact of the Quality of Higher Education on the Development of Regional Economy-Empirical Analysis Based on Provincial Panel Data
}

\author{
Xinyan $\mathrm{Xia}^{1, *}$ and Xiaodong Qiu ${ }^{1}$ \\ ${ }^{1}$ School of Economics and Management, Beijing Jiaotong University, Beijing, 100044, China \\ *Corresponding author. Email: 20120711@bjtu.edu.cn
}

\begin{abstract}
In the context of the era of knowledge economy, most scholars generally agree that a thriving education makes a flourishing country, but few have noticed that the quality of higher education is diverse and complex. Under the background, we divide the quality of higher education into teaching quality and scientific research quality, studying the impact and contribution of higher education quality to regional economic development to help colleges and universities find the direction and focus of future development. This paper uses panel data about 31 provinces from 2012 to 2018 and uses an improved C-D model to study the impact and contribution of teaching quality and scientific research quality to regional economic development. The empirical results show that the quality of teaching and scientific research in higher education is positively correlated with regional economic development, and the contribution of scientific research quality to regional economic development is bigger than that of teaching quality. So we conclude that the improvement of teaching quality and the improvement of scientific research quality can promote the development of the regional economy to a certain extent, and the contribution rate of scientific research quality is higher.
\end{abstract}

Keywords: Higher Educational Quality; Teaching Quality; Scientific Research Quality; Regional Economic

\section{Development; Contribution}

\section{INTRODUCTION}

A thriving education makes a thriving country, while a powerful education makes a powerful country. The development level of higher education is an important indicator of a country's progress and potential, especially higher education, which is at the top of the educational pyramid reflects the level of development and development potential of a country. Since the reform and opening up, the relationship between higher education and regional economic development has become closer and closer. On the one hand, higher education can cultivate various highquality professionals needed by society. On the other hand, it can transform the scientific research results of higher education into production factors to promote the development of the national economy. As early as the 1990s, China put forward the "Strategy for Rejuvenating the Country through Science and Education", and expanded higher education in 1999. After more than 20 years of development, the scale of higher education in China has ranked first in the world, but the quality of education is difficult to guarantee. Under the new normal situation, the quality of higher education has become a hot spot of social concern, and it is imperative to study the internal relationship between the quality of higher education and regional economic development.
Facts and experience show that if the region has a high quality of higher education, the level of regional economic development would be higher, such as Beijing and Shanghai, which gathered so many high-quality educational resources. The quality of education is diversified and complex, and which aspects have an impact on regional economic development or the extent of the impact is unknown. To further study the relationship between the quality of higher education and regional economic development, this paper uses 31 provincial panel data from 2012 to 2018 to explore the relationship between them from an empirical point of view.

\section{LITERATURE REVIEW}

There are extensive discussions on higher education and economic development, and most of the current research is from the perspective of human capital. For example, Yangxi Liu and Ganyu Liu[1], based on the human capital perspective, found that the development of higher education is significantly positively correlated with regional economic development. Lianghua Li, Shanshan Yang, and Xue Li [2] used the theory of human capital to find that human capital accumulation plays a role as a bridge between higher education and economic structure optimization, and it can promote the mutual influence and transformation between them. Due to the imbalance of 
regional economic development in China, many scholars have studied the relationship between higher education and economic development from the perspective of geographic location. Xiaodong Zhu, Zhongjia Zhang, and Lijun Wang [3] used an improved C-D production function model to investigate the difference in the contribution rate of higher education to economic development in different regions in the east, middle and west of China. Yangxi Liu and Ganyu Liu [1] also found that geographic location has a moderating effect between higher education and regional economic development. Fuying Wang [4] selected 10-year panel data from 12 western provinces, used a fixed-effect model, and found a positive correlation between higher education manpower input and regional economic growth. Although the research on higher education and economic development is mostly at a macro level, Chunping Chen and Heqiong $\mathrm{Hu}$ [5] analyzed the structure and levels of higher education from a mid-level perspective, and divided higher education levels into junior college students, undergraduates, and postgraduates. The study found that China's higher education level still lags behind economic development, and the hierarchical structure of higher education is significantly positively correlated with economic development.

Although there are extensive discussions on higher education and economic development, there are few studies on the quality of higher education and economic development. In 2009, Hanushek and Weissman began to study the relationship between education quality and economic development. Yonghong Zhou and Yang Xiong [6] used panel data to regress and found that compared with the scale of higher education, the quality of education has a greater effect on promoting economic development. Shuohao Li and Lele Geng [7] used Denison's factor analysis method and found that the contribution of higher education to economic growth after enrollment expansion was only $2.7 \%$. Juan Nie and Shibo Xin [8] through the cluster analysis found that the quality of higher education in various provinces and cities has regional differences in the effect of economic development, and the transformation of human capital economic results will be affected by regions.

The effect of the quality of higher education on regional economic development cannot be ignored. Nevertheless, through literature review, it can be seen that previous studies on the quality of higher education and regional economic development have regarded the quality of higher education as a whole, and did not examine the contribution to economic development from different aspects of higher education quality. So this article divides the quality of higher education into two dimensions, teaching quality and scientific research quality, to study the impact of higher education quality on regional economic development.

\section{MODEL AND DATA}

\subsection{Model}

This article uses Douglas production function as a research model to measure the impact of higher education quality on regional economic development, and introduces higher education quality (teaching quality and scientific research quality) factors into the $\mathrm{C}$-D production function measurement model, as shown in the formula:

$$
\mathrm{Y}=\mathrm{A} \mathrm{K}^{\alpha} L^{\beta}
$$

In this formula, $\mathrm{Y}$ represents total output, A represents technological progress $(A=1), K$ represents capital input level, the index $a$ represents the elasticity coefficient of capital output, $\mathrm{L}$ represents labor input level, and $\beta$ is the elasticity coefficient of labor output. The teaching quality in higher education quality changes the quality level of the labor force directly or indirectly, so the labor input level L in the formula can be replaced by the product of the labor input amount $\mathrm{L}_{0}$ and the teaching quality $\mathrm{E}$ of the year. Although the quality of scientific research in higher education can promote technological progress, it cannot represent the level of technological progress. Therefore, a new variable $\mathrm{R}$ is introduced for the formula here, representing the quality of scientific research. So a new measurement model (2) can be obtained:

$$
\mathrm{Y}=\mathrm{A} \mathrm{K} \mathrm{K}^{\alpha} \mathrm{L}_{0}^{\beta} \mathrm{E}^{\theta} \mathrm{R}^{\gamma}
$$

Using the C-D production function, calculate the ratio of the level of the regional economic development brought about by the quality of higher education. Therefore, take the logarithms on both sides of the model to obtain the model (3):

$$
\operatorname{LnY}=\alpha \operatorname{LnK}+\beta \operatorname{Ln} L_{0}+\theta \operatorname{LnE}+\gamma \operatorname{LnR}
$$

$\mathrm{LnY}$ is the annual growth rate of the regional economy, $\mathrm{LnR}$ is the rate of progress in scientific research quality, $\mathrm{LnK}$ is the annual growth rate of capital input, $\mathrm{LnL}_{0}$ is the annual growth rate of labor input, $\mathrm{LnE}$ is the rate of improvement in education quality, $\alpha$ represents the elasticity of capital output, and $\beta$ represents the elasticity of labor output, $\theta$ represents the elasticity of teaching quality output, and $\gamma$ represents the elasticity of scientific research quality output.

\subsection{Variable Measurement and Data Source}

This article mainly involves five variables. Y represents the total output. We uses GDP to quantify total output learning from the research of Shuohao Li and Lele Geng[7]. K stands for capital investment, borrowed from the research of Juan Nie and Shibo Xin [8] and measured with the fixed asset investment of the whole society. L stands for labor input, which is quantified by the number of employed 
persons in urban units. E stands for teaching quality, which is measured by the student - teacher ratio. It should be noted that the student - teacher ratio here is an inverse indicator of teaching quality. $\mathrm{R}$ stands for the quality of scientific research, and the scientific research expenditures of universities are used here to quantify.

The data on total output, capital input and labor are from the "China Statistical Yearbook", and data on the quality of teaching and scientific research are from the official website of the Ministry of Education.

Table 1. Variable

\begin{tabular}{|c|c|c|}
\hline Variable & Code & Index \\
\hline Total Output & Y & GDP \\
\hline $\begin{array}{c}\text { Teaching } \\
\text { Quality }\end{array}$ & E & $\begin{array}{c}\text { Student - teacher ratio. (It is a } \\
\text { reverse index.) }\end{array}$ \\
\hline $\begin{array}{c}\text { Research } \\
\text { Quality }\end{array}$ & R & $\begin{array}{c}\text { Scientific research expenditures } \\
\text { of universities. }\end{array}$ \\
\hline Capital Input & K & $\begin{array}{c}\text { Fixed asset investment of the } \\
\text { whole society. }\end{array}$ \\
\hline Labor Input & L & $\begin{array}{c}\text { The number of employed } \\
\text { persons in urban units. }\end{array}$ \\
\hline
\end{tabular}

\section{EMPIRICAL ANALYSIS}

\subsection{Hypotheses}

Both Rong Miao [9] and Guocang Li [10] believe that the quality of higher education mainly depends on academics and talents, so this article divides the quality of higher education into two dimensions: scientific research quality and teaching quality. The New Economic Growth Theory believes that human capital is an endogenous variable of economic growth, and one of the main functions of higher education is to train and transport talents to the society. High-quality higher education can promote the improvement of workers' knowledge and skills, cultivate the talents to the society, and promote regional economic development. In addition, high-quality higher education can also indirectly attract potential educators to invest in education and promote regional economic development. So we propose hypothesis 1: Teaching quality is positively correlated with regional economic development.

The main body of higher education is the university, which is a special cultural institution. In addition to the function of cultivating talents, the university also has the function of scientific research. The high-quality performance of higher education in scientific research means that it can improve the quality and speed of the transformation of research results into productivity and promote regional economic development. In addition, if we have high quality of scientific research, we can study cutting-edge advanced technologies, further promote the production of research results, form a virtuous circle between scientific research and regional economic development to drive economic development further. Therefore, we propose hypothesis 2 :
The quality of scientific research is positively correlated with regional economic development.

\subsection{Descriptive Statistics}

Table 2 is the average value of the measurement indicators of each variable in 31 provinces from 2012 to 2018. From the table2, it can be seen that the total GDP output, the student - teacher ratio and the scientific research expenditures of universities are all in rising year by year. And the expenditures for advanced scientific research began to sharply increase in 2016 due to the 13th Five-year Plan on Technology and Innovation in 2016.

Table 2. Descriptive Statistics

\begin{tabular}{|l|l|l|l|l|c|}
\hline Year & \multicolumn{1}{|c|}{ Y } & \multicolumn{1}{c|}{ E } & \multicolumn{1}{c|}{ R } & \multicolumn{1}{c|}{ L } & K \\
\hline 2012 & 18598.45 & 15.918 & 441232.8 & 425.81 & 11889.95 \\
\hline 2013 & 20462.75 & 16.006 & 452762.7 & 705.065 & 14214.15 \\
\hline 2014 & 22075.79 & 16.128 & 450826.7 & 805.642 & 16314.58 \\
\hline 2015 & 23315.090 & 16.371 & 444120.8 & 905.707 & 17949.91 \\
\hline 2016 & 25163.550 & 16.413 & 465138.3 & 995.461 & 19389.92 \\
\hline 2017 & 27327.1 & 16.54 & 543672.2 & 1100.229 & 20516.71 \\
\hline 2018 & 29506.69 & 22.202 & 650002.1 & 1206.868 & 21748.61 \\
\hline
\end{tabular}

\subsection{Correlation Analysis}

Table 3 is a correlation analysis of variables. From Table 3, we can see that the student - teacher ratio is negatively correlated with total output, which means teaching quality is positively correlated with regional economic development. The correlation coefficient between total output and university scientific research expenditure is greater than 0 , so there is a positive correlation between total output and scientific research quality. The absolute value of the correlation coefficient of scientific research quality is greater than the absolute value of teaching quality, so we make a preliminary judgment that the contribution of scientific research quality to regional economic development is greater than the contribution of teaching quality to regional economic development.

Table 3. Correlation Statistics

\begin{tabular}{|l|l|l|l|l|l|}
\hline & \multicolumn{1}{|c|}{$\mathbf{Y}$} & \multicolumn{1}{|c|}{$\mathbf{E}$} & \multicolumn{1}{|c|}{$\mathbf{R}$} & \multicolumn{1}{|c|}{$\mathbf{L}$} & $\mathbf{K}$ \\
\hline $\mathbf{Y}$ & 1 & & & & \\
\hline $\mathbf{E}$ & -0.0081 & 1 & & & \\
\hline $\mathbf{R}$ & 0.565 & -0.126 & 1 & & \\
\hline $\mathbf{L}$ & 0.938 & -0.0073 & 0.524 & 1 & \\
\hline $\mathbf{K}$ & 0.867 & 0.0099 & 0.380 & 0.792 & 1 \\
\hline
\end{tabular}

\subsection{Regression Analysis}

The regression results in Table 4, R2 $=0.927$, it proves that the model fits well. Observing the standardized regression results, we can see that the total output is positively correlated with the quality of teaching and the quality of 
scientific research at the $1 \%$ significance level. In order to make the research results of this article more robust, we take the method of replacing the independent variables to regress again. Therefore, we replace the scientific research funding expenditure with the index of university scientific research personnel input.(RH). The regression result is the same as before, which further confirms the positive correlation between regional economic development and the quality of teaching and scientific research.

Table 4. Regression Results

\begin{tabular}{|c|c|c|}
\hline & $\begin{array}{c}\text { Regression } \\
\text { Analysis } \\
\end{array}$ & $\begin{array}{c}\text { Robustness } \\
\text { Test }\end{array}$ \\
\hline VARIABLES & $\boldsymbol{Y}$ & $Y 2$ \\
\hline \multirow[t]{2}{*}{$\mathrm{E}$} & $-0.099 * * *$ & $-0.097 * * *$ \\
\hline & $(-4.38)$ & $(-3.89)$ \\
\hline \multirow[t]{2}{*}{$\mathrm{R}$} & $0.186 * * *$ & \\
\hline & $(5.56)$ & \\
\hline \multirow[t]{2}{*}{ RH } & & $1.125 * * *$ \\
\hline & & $(4.87)$ \\
\hline \multirow[t]{2}{*}{$\mathrm{L}$} & $0.354 * * *$ & $0.346 * * *$ \\
\hline & $(6.81)$ & $(8.24)$ \\
\hline \multirow[t]{2}{*}{$\mathrm{K}$} & $0.526 * * *$ & $0.617 * * *$ \\
\hline & $(8.87)$ & $(14.82)$ \\
\hline \multirow[t]{2}{*}{ Constant } & $2.594 * * *$ & $5.180 * * *$ \\
\hline & $(8.29)$ & $(8.80)$ \\
\hline Observations & 214 & 217 \\
\hline R-squared & 0.928 & 0.925 \\
\hline F test & 0 & 0 \\
\hline $\mathrm{r}^{2} \_\mathrm{a}$ & 0.927 & 0.923 \\
\hline $\mathrm{F}$ & 417.4 & 652.9 \\
\hline
\end{tabular}

\subsection{Further Analysis}

We use the regression results to further analyze the contribution of teaching quality and scientific research quality to regional economic development. The results are shown in Table 5. From Table 5, it can be seen that the contribution rate of teaching quality to regional economic development is $8.52 \%$, and the contribution of scientific research quality to regional economic development is $15.94 \%$. It demonstrates that compared with the teaching quality, the quality of scientific research plays a stronger role in promoting regional economic development.

Table 5. Contribution

\begin{tabular}{|c|c|c|c|c|}
\hline VARIABLES & E & R & L & K \\
\hline Contribution & 0.0852 & 0.1594 & 0.3038 & 0.4516 \\
\hline
\end{tabular}

\section{CONCLUSION}

At present, many scholars have proved the importance of higher education quality to regional economic development from theoretical and empirical perspectives, but they have not examined the contribution rate of various aspects of higher education quality to regional economic development. Therefore, we conduct an empirical analysis based on the provincial panel data from 2012 to 2018. The results show that the quality of teaching and research has a significant positive correlation with regional economic development. And compared with the quality of teaching, the quality of higher education has made greater contributions to regional economic development.

\section{DISCUSSION}

Based on the above research results, we think China should develop our higher education to serve regional economic development better from the following aspects. First of all, policy-making departments should realize that the quality of teaching in higher education is one of the important driving forces for the development of the national economy. It is absolutely undesirable to blindly expand the scale of education and ignore the quality of education. Therefore, in the background of the current expansion of higher education, relevant universities should further increase the number of university teachers, maintain a low student - teacher ratio, and ensure the quality of teaching. Secondly, in the construction and development of universities, more attention should be paid to the quality of scientific research. The government and relevant departments should also increase the investment of scientific research funds in universities, so that more and more scientific research results can be invented and transformed, and scientific research in universities can drive scientific and technological innovation. In addition, relevant departments can also issue relevant policies to encourage university students with scientific research potential to further devote themselves to scientific research, expand the team of scientific researchers, and improve the quality of scientific research in universities. Universities should also actively seek cooperation with companies and run Production-Teaching-Research to obtain more funds and technical support to improve the universities' scientific research quality.

\section{REFERENCES}

[1] Yangxi Liu, Ganyu Liu, "The influence of higher education on regional economic development: an analysis with the perspective of human capital", Shanghai Journal of Educational Evaluation, vol.9, pp.1-6, 2020. DOI:

http://dx.chinadoi.cn/10.13794/j.cnki.shjee.2020.0001. (In Chinese)

[2] Lianghua Li, Shanshan Yang, Xue Li, "Human capital accumulation, economic structure transformation and higher education development", Finance and Economics, vol,392, pp. 122-132, 2020.DOI: 
http://dx.chinadoi.cn/10.3969/j.issn.10008306.2020.11.010. (In Chinese)

[3] Xiaodong Zhu, Zhongjia Zhang, Lijun Wang, "Research on the regional differences of China's higher education contribution to economic growth - based on the perspective of human capital output elasticity", Jiangxi Social Sciences, vol.34, pp.82-86, 2014. . (In Chinese)

[4] Fuying Wang, "An empirical study on the impact of higher education manpower input on regional economic growth - based on panel data of 12 western provinces and urban areas", Think Tank Era, vol.236, pp.6769,2020. . (In Chinese)

[5] Chunping Chen, Heqiong $\mathrm{Hu}$, "Research on the relationship between the optimization of the hierarchical structure of China's higher education and economic development", Forum on Contemporary Education, April 2021. DOI:

https://doi.org/10.13694/j.cnki.ddjylt.20210407.002. (In Chinese)

[6] Yonghong Zhou, Yang Xiong, "The impact of higher education quality on China's economic development - an empirical study based on interprovincial Panel Data", Journal of Hubei University(Philosophy and Social Science), Vol.40, pp.
114-119, Jul., 2013. DOI:

http://dx.chinadoi.cn/10.13793/j.cnki.42-

1020/c.2013.04.029. (In Chinese)

[7] Shuohao Li, Lele Geng, "Empirical research on the contribution rates of higher education to the economic growth after the expansion", Modern Education Management, vol.331, pp.29-34. 2017.DOI: http://dx.chinadoi.cn/10.16697/j.cnki.xdjygl.2017.10.00 6. (In Chinese)

[8] Juan Nie, Shi-bo Xin, "Analysis of quality differentiation measurement in higher education in China and its effect on regional economic growth", China Soft Science, vol.335, pp.58-65,2018. DOI: http://dx.chinadoi.cn/10.3969/j.issn.10029753.2018.11.007. (In Chinese)

[9] Rong Miao, "Discuss on the quality standards of higher education legal system and society", Legal System And Society, vol.10, 2008. DOI: http://dx.chinadoi.cn/10.3969/j.issn.10090592.2008.29.178. (In Chinese)

[10] Guocang LI, "Discuss on one central and two basic points of talent cultivation in higher education", China Higher Education Research, vol.258, pp.54-58, 2015. DOI: http://dx.chinadoi.cn/10.16298/j.cnki.10043667.2015.02.12. (In Chinese) 